\title{
Factors Associated with Improvement in Patient- Reported Outcomes After Receiving Early Palliative Care
}

\author{
Rodin R, Swami N, Pope A, Hui D, Hannon B, Zimmermann C
}

University of Toronto, Department of Medicine, University Health Network, Toronto, Canada

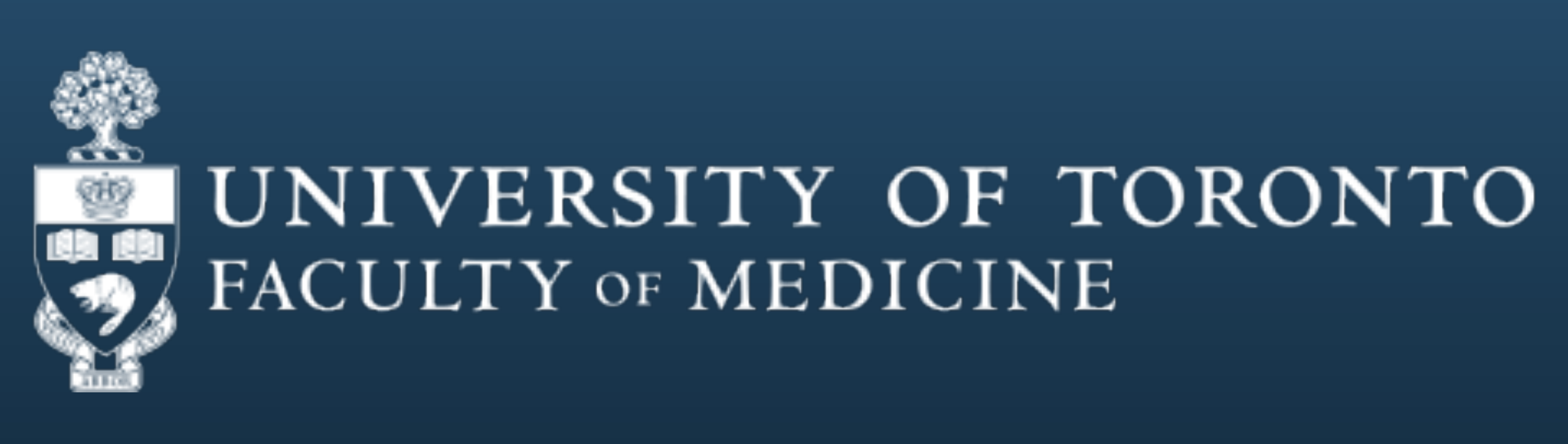

\section{Background}

\section{Definition}

- Early palliative care (EPC) is that implemented at the time of, or shortly after, diagnosis of advanced disease

\section{International Support}

- Specialized EPC is a widely accepted, evidencebased global initiative that improves quality of life and symptom burden in advanced cancer ${ }^{1,2}$

-WHO (2010): recommended for all lifelimiting illnesses

- ASCO (2017): recommended as concurrent with active treatment in advanced cancer

\section{Study Rationale}

- EPC improves quality of life and symptom burden but universal implementation is impractical

Barriers to Universal Implementation

- Cost and time efficiency

- Limited human resources

- Potential duplication of services

- Feasibility across different settings

Potential Solution

- Targeting patients most likely to benefit from early intervention

\section{Purpose}

To determine predictors of EPC treatment response at 4 months in advanced cancer patients

\section{Methods}

\section{Study Design}

- Secondary analysis of cluster-randomized trial (Zimmermann et al 2014) ${ }^{3}$

Study Sample

- 131 patients with advanced cancer randomized to EPC intervention

\section{EPC Intervention}

- Consult by palliative MD and nurse within 1 month of diagnosis + routine follow up

Eligibility Criteria

- Inclusion

- Exclusion

$\cdot \geq 18$ years old

- Insufficient

- Stage IV or equivalent English literacy

- ECOG 0-2

- Cognitive

- 6-24 months survival

\section{Baseline Demographic Data}

\begin{tabular}{|l|l|}
\hline Patient Characteristics & $(\%)$ \\
\hline Mean Age (range; years) & $60 \pm 11$ (30-84) \\
Female & 64 \\
Married/Common Law & 66 \\
Living Alone & 23 \\
Employment Status & \\
$\quad$ Retired & 40 \\
Employed & 22 \\
$\quad$ Unemployed & 13 \\
$\quad$ Disability & 25 \\
College/University Educated & 73 \\
& \\
Ethnicity & \\
$\quad$ N. American & \\
$\quad$ European & Asian \\
Other & 30 \\
& 49 \\
\hline
\end{tabular}

\begin{tabular}{|l|l|}
\hline Cancer Profile & $(\%)$ \\
\hline Primary Tumour Site & \\
\hline Breast & 21 \\
GI & 30 \\
GU & 11 \\
Lung & 15 \\
\hline Gynecological & 23 \\
\hline Active Chemo & 79 \\
\hline Active radiation & 7 \\
\hline CCI Score $>0$ & 29 \\
\hline ECOG Score & \\
0 & 33 \\
1 & 63 \\
2 & 4 \\
\hline
\end{tabular}

\section{References}

${ }^{1}$ Bakitas et al. Effects of a palliative care intervention on patients with advanced cancer: the Project ENABLE II randomized controlled trial. JAMA 2009;302:741-49.

2. Temel et al. Early palliative care for patients with metastatic nonsmall-cell lung cancer. N Engl J Med 2010;363:733-42.

${ }^{3}$ Zimmermann $\mathrm{C}$ et al. Early palliative care for patients with advanced cancer: a cluster-randomised controlled trial. Lancet 2014;383:171-30

\section{Acknowledgements}

This study was funded by the Canadian Cancer Society and the Canadian Institutes for Health Research

\section{Predictors of Treatment Response}

Quality of life

- FACIT-Sp:

- More severe baseline physical symptoms (ESAS-EDS) $(p=0.001)$

- QUAL-E:

- Less medical comorbidity $(\mathrm{CCl})$ $(p=0.045)$

Symptom severity (ESAS-EDS)

- More severe baseline physical symptoms (ESAS-EDS) $(p<0.001)$

- Less medical comorbidity $(\mathrm{CCl})$ $(p=0.007)$

Satisfaction with care (FAMCARE-P16)

- Living alone $(p=0.03)$

- Not receiving active chemotherapy $(p=0.03)$

* No effect for age, sex, primary tumour site, or education/employment status

\section{Discussion}

- Patients with greater symptom burden and support needs (i.e. living alone) are most likely to benefit from EPC

- The finding that symptom severity predicts response on FACIT-Sp but not on QUAL-E may be explained by differences in the domains assessed by each measure

- QUAL-E - includes life completion, preparation for end of life

- FACIT-Sp - includes physical and emotional quality of life

Strengths

- Large sample

- Validated measures

- Data based on rigorously conducted RCT

- High quality EPC Intervention

\section{Future Directions}

- Establishing evidence-based cutoffs on symptom screening to maximize benefit from EPC

- Greater specification of support needs and optimal interventions in patients with low social support

- Clarifying the role of EPC on comorbid conditions 